\title{
Research on the Reform of the Elective Course of Football in Colleges and Universities
}

\author{
Juhai Wang \\ Institute of Physical Culture, Weinan Normal University, Weinan, Shaanxi, 714099
}

\author{
Keywords: Ordinary Colleges; Football Elective Courses; Curriculum Reform
}

\begin{abstract}
The reform of Chinese football has led to the rise of football in colleges and universities. The country has carried out drastic reforms in the football system, football management, and football talent training. Colleges and universities have become an important base for the reserve of football talents in China. In this sense, colleges and universities football teaching will have an important impact on China's football career. However, in ordinary colleges and universities, football teaching is mostly for exam-oriented education, especially as an elective course. Football lessons not only lack the teaching atmosphere, but also cannot guarantee the quality of teaching. Therefore, it is also very unfavorable for the cultivation of football talents. The paper mainly discusses the problems existing in the teaching of football elective courses in colleges and universities in China at present, including lack of resources, single teaching content and teaching methods, and lack of scientific evaluation system, and proposes specific improvement measures for these problems.
\end{abstract}

\section{The Problems in College Football Elective Courses}

The lack of teaching resources for college football is mainly reflected in the weak teachers, the lack of resources for students and the low learning time. First of all, the teacher is the leader in football teaching and the instructor of football technology. The teacher's own professional ability will have a direct impact on the effect of students learning football skills. However, as an elective course, usually a football teacher in a university needs to teach several classes at the same time, and many football teachers are not football majors. Their knowledge structure and professional skills cannot meet the actual teaching needs, so the teaching effect cannot be guaranteed. Secondly, as an elective course, students' interest in football is also relatively weak. The ranking of Chinese football in the world has been unsatisfactory, and few have achieved good results in major world events. The patience and interest of Chinese people in football has also more and more low, the number of students who are willing to choose football lessons under the influence of this kind of thinking is getting less and less. Some students who choose football lessons are only for the purpose of taking credits. In addition, football itself is a sports project, which requires a lot of time and energy in the learning process. The number of students who learn football is small, and it is difficult for students to find people who play together. Therefore, the more students are interested in football. The smaller it is. Finally, there is less teaching time and there is no guarantee of practice time. The football course in colleges and universities is only an elective course. Most colleges only have one class per week, and each class is only 90 minutes. It is difficult for teachers to teach more theoretical knowledge and student training time in such a short period of time. It is also seriously inadequate. During the class time, the teacher needs to instruct the students to carry out a large number of classroom exercises in order to find out the shortcomings of the students' skills in a timely manner. Therefore, the short class time becomes an important factor affecting the teaching effect of the football class.

At present, the football elective courses in ordinary colleges and universities are still based on the traditional teacher, student listening, and retraining modes. Under the guidance of the syllabus, the teacher teaches students relevant knowledge of football, such as development history, competition rules, training skills, and related. Precautions, etc., theoretical knowledge is boring, students can only passively accept in the classroom; and as an elective course, there is only one 90-minute football class per week, and students lack sufficient training time. The disadvantages of 
traditional teaching methods that are too professional and boring in content are undoubted. Over time, students will not be interested in football courses, which directly affect the quality of football teaching.

Assessment is the supervision and feedback of learning. The standardized assessment system is an important guide for the formulation of teaching objectives and teaching strategies. However, at present, the evaluation methods for football elective courses in most ordinary colleges and universities in China are still based on summative evaluation, only student movement. The score is a single evaluation index, ignoring the progressive evaluation. Most students evaluate the students' academic performance by the student's attendance rate, classroom impression and the final test of one or two football skills. This single evaluation method is not only true to the students. The level of football sports is objective, accurate and comprehensive, and it will affect students' enthusiasm for learning because of unscientific evaluation.

\section{The Reform Strategy of Football Elective Courses in Colleges and Universities}

In view of the problems existing in the college football elective courses, it is recommended to carry out reforms in the following aspects to improve the effectiveness of football teaching:

The teaching goal of the college football elective course is to enable students to master the relevant theoretical knowledge of sports and sports skills, so as to promote their active participation in sports activities, physical fitness, and ultimately achieve the goal of comprehensive fitness. The football elective course has built a good platform for students to not only improve their football skills, but also cultivate their awareness of lifelong sports. Therefore, ordinary colleges and universities should carry out new curriculum design and arrangement for football lessons. Through questionnaires to understand the purpose and needs of students' elective football courses, and then dynamically adjust the teaching plan with the syllabus, so that the teaching content is closely related to the needs of students. Introduce advanced teaching concepts in daily teaching, such as the choice of courses by students, the implementation of small class group training, etc., through the forward-looking teaching concept to improve students' acceptance of football elective courses. In addition, colleges and universities must also create a good football culture on campus, so that students pay attention to football and love football from the concept. The school should actively carry out extracurricular activities related to football projects, such as setting up a campus football club, regularly organizing football matches between classes, college games and football matches between colleges, etc., and providing more practical training for students through large and small competitions. The opportunity to stimulate their interest in learning forms a good campus football development atmosphere within the school. When the conditions permit, increase the time of the football elective course and reserve more study time for the students. If the conditions are not allowed, the teacher should actively study advanced teaching methods and reasonably arrange football homework to compensate for the lack of teaching time.

Football is a highly confrontational, technically complex, tactical and diverse sport. It not only has a long game time, but also has high requirements for the venue. In the football teaching activities, it is necessary to adopt a variety of teaching methods according to the characteristics of football. Enrich the teaching content to stimulate students' interest in learning and improve teaching results. First of all, teachers should consciously explore some interesting content of the curriculum, organize teaching through contextualization, gamification, and competition. Of course, the whole process must always run through the concept of competition and application, and guide students to master solid basic technology. Secondly, the teaching content is also carried out around the theoretical system of football, and the combination of theory and practice is achieved. For example, when teaching the ball skills, the main goal is to improve the ball passing skills and cultivate students' practical ability. Therefore, in actual teaching, students can be divided into a number of groups with equal numbers for the ball game. The team will win the most in the specified time. During the pass and stop training, the students are also divided into two equal teams, standing on two venues, three people forming three triangle rings $10 \mathrm{~m}$ apart, the rest standing at the starting point, the teacher asked the two teams to pass the ball. In the stop-and-go game, the student at the 
starting point passes the ball to the first person in the triangle ring and runs into the position where the first person stands. The first person then passes the ball to the second person and runs into the second person. The position of standing, and so on, is repeated until each person returns to the original position, and the least time is used to win. The whole teaching process not only pays attention to the theoretical mission, but also provides students with more practical training opportunities. The competitive technical training can greatly stimulate students' interest in learning, so that students can truly learn to play and learn to play football. Finally, multimedia technology can also be used to intuitively explain some tactical strategies and sports skills in football. In the classroom, students can play video of the competitions of major events, and decompose the techniques of dribbling, passing, passing, shooting, etc., which are frequently used and have high success rate, so that students can understand complex technical links through intuitive pictures. If conditions permit, students can be organized to watch live broadcasts, and explain the technical and tactical use strategies in combination with the specific conditions of the competition to deepen students' rational cognition of football and stimulate their interest in learning.

The educational concept of college physical education adheres to the guiding ideology of "health first", and promoting the healthy growth of students is the ultimate goal of physical education in colleges and universities. The evaluation of students' learning outcomes in football elective courses should also be guided by this goal, through theory and practice. The combined evaluation system stimulates students' interest in learning and obtains objective and real feedback in a timely manner. Specifically, the evaluation index system combining theory and practice includes sports participation, physical health, mental health and social adaptation. Sports participation mainly evaluates students' interest in participating in sports and promotes them to develop good exercise habits and sports awareness. In the evaluation, it is necessary to see the positive level of students participating in the football course, and whether the correct method can be used for football. Physical health indicators include whether the student's physical posture is correct during football, whether physical fitness has been developed, and whether he has mastered the theoretical knowledge related to football. Mental health indicators refer to whether students understand the positive effects of football on people's mental health, whether they can accurately understand the relationship between football and self-esteem and self-confidence, whether they can regulate emotions through football, and cultivate strong will qualities. The social adaptation index refers to whether students have established a harmonious interpersonal relationship with other students through football, whether they have good sportsmanship and sports ethics, and whether they have acquired relevant sports health knowledge through football. The above four evaluation indicators not only pay attention to the physiological and health development of students, but also take into account the students' mental health and social adaptability, and comprehensively evaluate the students' learning outcomes. In the specific evaluation, individual evaluation methods such as individual self-assessment, peer-to-peer evaluation, group evaluation, group evaluation, and teacher evaluation can be combined to finally obtain an objective and scientific evaluation result.

\section{Conclusion}

In short, colleges and universities as the main position to cultivate high-quality talents, university sports should also develop towards the direction of happy sports, culture and sports, and life sports. In today's football development in China, it is of great practical significance to carry out football elective courses in colleges and universities. Of course, as an elective course, the problems of insufficient resources, backward teaching methods, single teaching content, and unscientific evaluation system cannot be ignored. As a football teacher, we must face up to these problems and continue to explore in the teaching practice, deeply understand the teaching philosophy of the new curriculum reform, fully respect the main role of students in the football class, emphasize the individual needs of students, and constantly improve the teaching methods. Students not only have to master the relevant technology of football, but also have a comprehensive understanding of the theoretical knowledge of football. For example, how to analyze the method of kicking high quality ball through exercise mechanics, so that students can master more sports physiology knowledge, 
know how to prevent sports injuries, etc. Inspire students' interest in learning, thus improving the quality of teaching in football elective courses.

\section{Acknowledgements}

Fund Project: This work was financially supported by Basic Research Projects of Weinan Technology Bureau (2017JCYJ-2-5), Education Science International Cooperation Research Projects of Weinan Normal University (17GJHZ15) and Shaanxi Social Science 2018 Projects of Major Theoretical and Practical Problems Research (2018Z001).

\section{References}

[1] Wang Bo, Zhou Xuerong, Li Huimeng. Confusion and Reflection on the Setting of College Physical Education Curriculum from the Perspective of "Sunshine Sports"[J]. Journal of Beijing Sport University, 2014(5): 112-117.

[2] Xia Qing, Qin Xiaoping, Zhang Bin. Development and Optimization of Five-a-side Football Curriculum Resources in Colleges and Universities [J]. Contemporary Sports Science and Technology, 2013(36): 40-41

[3] Jiang Xuelai, Wang Guozun, Lin Zhizhong. Investigation and Reform Suggestions on the Current Situation of Football Courses in Colleges and Universities in Fujian [J]. Journal of Sanming University, 2016, 23(02).

[4] Sun Qingwu.Discussion on the Teaching System and Reform of Physical Education Curriculum in Colleges and Universities [J]. Journal of Xil'an Institute of Physical Education, 2014, (5):22-24.

[5] Li Haozhi, Cao Hanhu. Research on the Evaluation System of Football Specialized Courses in Colleges and Universities [J]. Journal of Wuhan Institute of Chemical Technology, 2016, 28(5): 123-125.

[6] Wang Jian.Reconstruction and Reconstruction of Chinese PE Teaching Objectives under the New Curriculum Concept [J].Journal of Xil'an Institute of Physical Education, 2017,20(3):77.

[7] Liu Zhongliang. The Idea of Developing Football in Colleges and Universities [J]. Hubei Teachers College, 2017, 17(4): 108-110.

[8] XIONG Jianping, ZHOU Mingxing. Thoughts on Chinese College Students' Football Movement[J].Journal of Shandong Physical Education Institute,2016,17(4):23-24. 